$\S=-1$

\title{
Investigation of Energy Values in Tender Coconut by Various Methods
}

\author{
"Yakkala MK Raghunadh ${ }^{1},{ }^{2}$ Neeluri Suresh, ${ }^{3}$ Mohd Mujtaba Ahmed, ${ }^{4}$ Konduru Ashok,,${ }^{5}$ A.Indra reddy \\ ${ }^{*, 2,3}$ Assistant Professor, Department of Mechanical Engineering, Guru Nanak Institutions, Hyderabad-501506 \\ ${ }^{4}$ Assistant professor, Department of Mechanical Engineering, Audisankara institute of Technology, Guuduru \\ ${ }^{5}$ Assistant Professor, Department of mechanical Engineering, KLEF, Vaddeswaram-522502 \\ *Corresponding author E-mail: email:raghuy363@gmail.com,Hyderabad-501506,sureshneeluri@gmail.com,mohd- \\ mujtabaahmed5@gmail.com,konduruashok308@gmail.com,alugubellyindrareddy@gmail.com
}

\begin{abstract}
Even in 2017 many rural areas the daily food preparation works on conventional furnaces and peat coal as the fuel. It releases lot of smoke and harmful gases. The village blacksmith work also depends on peat coal. One of the alternative fuels for conventional furnace is tender coconut fuel. The tender coconut having lot of mineral values in addition to that it having lot of fuel values. The availability of tender coconut is round the year. In most of the cases these coconuts after drinking simply dumping in the municipal waste or dumping at out cuts of the cities. By making simple process we can convert this tender coconut into good fuel. A special machine designed for process of tender coconut. A detailed analysis done on the tender coconut in two different ways. The total coconut analysis is done two ways, one is on direct coconut where as other is individual elements of the coconut analysis like shell, inner coir, outer coir and coconut husk. The calorific value of each one calculated by using the bomb calorimeter. The exhaust gases also analyzed y using exhaust gas analyzer.
\end{abstract}

Keywords: Analysis;bomb calorimeter;coconut;exhaust;Furnace.

\section{Introduction}

The cities like Hyderabad, Chennai and Coimbatore facing so many major problems, among that is municipal wastage dumping. Compare to normal days in more sunny days or summer session the wastage increase more and more because of tender coconut. The weight of tender coconut is more compared to dried coconut When these added into waste the quantity of the mass increases due to its size. Tender coconuts having lot of fuel values, we are losing this fuel by simply dumping into the dumping yard.

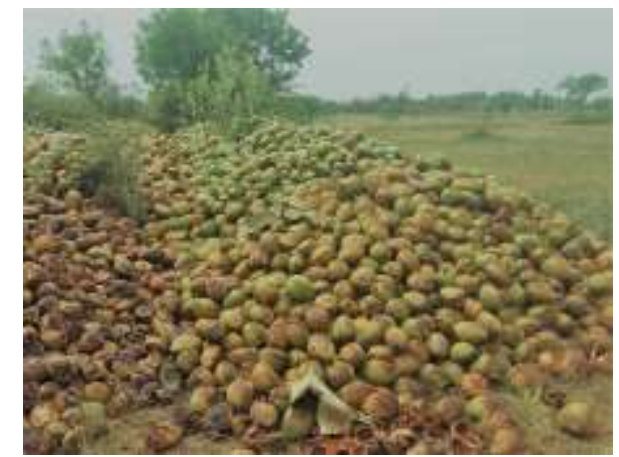

Figure:1. A sample dump of tender coconut at Hyderabad

We can convert tender coconut into high worth fuel by different processes. The tender coconut having various parts like outer skin, coir, shell and husk. Generally the shell having high calorific [1] value compare to remaining parts of the coconut. Generally the shell calorific value of coconut in the range of 18.2 to $20.8 \mathrm{Mj} / \mathrm{Kg}$. This value is highly sufficient for domestic heat application. The tender coconut shell calorific value is slightly lower to coconut shell value. The ash content is very less when compare to normal conventional coal.

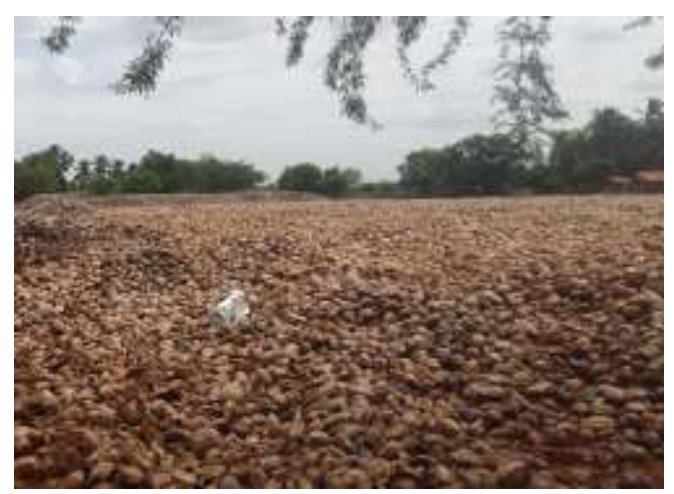

Figure:2. A sample dump of tender coconut at Coimbatore

The street merchants simply leaving used tender coconuts to municipal people or some time they are paying some amount to municipal people to take them. We have to collect them. So the cost of the tender coconut almost free. Loading into truck and dumping in open space and leave them to sunlight minimum 4 to 7 days one case the other one is applying sun light 14 to 18 days depends on sunlight. This transportation process little expensive. After sunlight case 1 is directly sending to pre heat chamber to reduce other moisture and unwanted matter from coconut. 


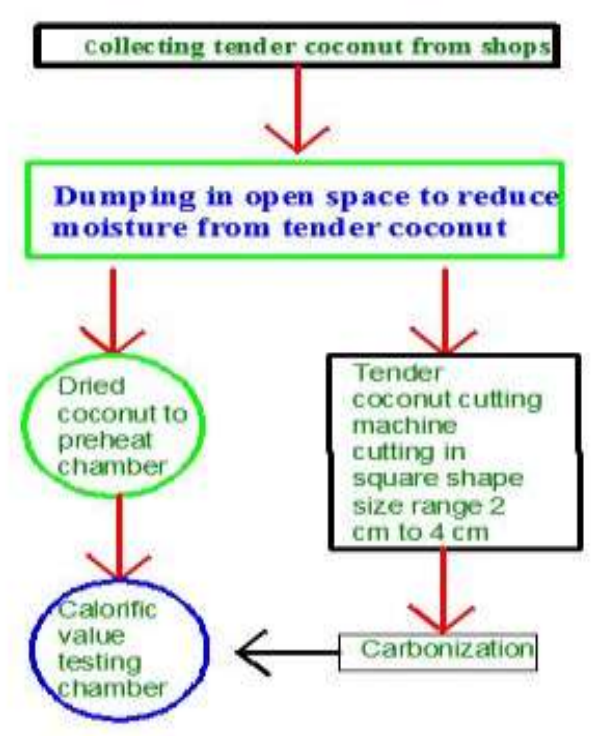

Figure:3. Total process lay out of the project

After 4 or 5 days the second case cutting into square pieces 2 to 4 $\mathrm{cm}$ size. After cutting process these chips again applying sunlight [10] because of this process the size of the pieces shrinks. These pieces sending to carbonization chamber there the ash content reduced and calorific value increase. The annual production of tender coconut sees from table no: 1 .

Table:1. The Annual production rate of tender coconut in million tons.[1]

\begin{tabular}{|cl|c|}
\hline \multicolumn{2}{|c|}{ state } & $\%$ of production \\
\hline 1. & Kerala & $52 \%$ \\
\hline 2. & Karnataka & 17.5 \\
\hline 3. & Andhrapradesh & 9.5 \\
\hline 4. & Maharashtra & $2.5 \%$ \\
\hline 5. & Tamilnadu & 18.5 \\
\hline
\end{tabular}

\section{Experimental analysis:}

The process may take 12 hours to 3 days to supply sufficient amount heat in coconut form and for square type of pieces. Due to pre heating and carbonization the ash value will reduce and efficient combustion and heat value will increase. The preheated and carbonized square type's pieces are making into power form with the help of hammering[11] force. Each and individual is measured in bomb calorimeter. The calorific value of each part of the coconut measured separately and indicated in Table:2. The combination of all the parts of the coconut powder also measured in calorimeter.

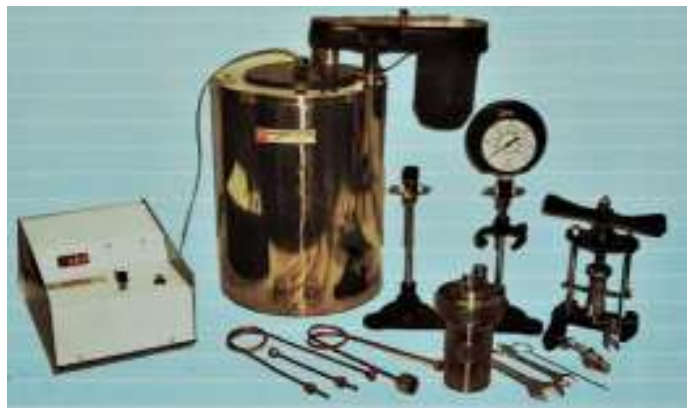

Figure: 4.Digital Bomb calorimeter [8]

After calculating calorific value a model furnace prepared. It is almost similar to conventional furnace. Initial firing given with the help of oil like power plant starting ignition. The combustion process is carried out at particular temperature and pressure. The exhaust gas is measures with the multi gas analyser. Compared to conventional fuel the coconut fuel reduces the exhaust and release very less harmful gases.

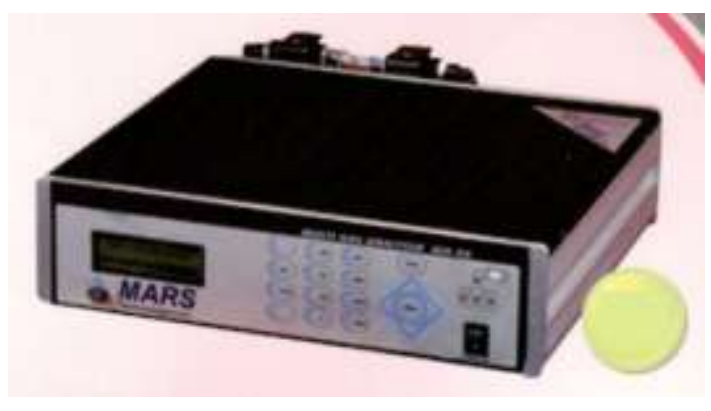

Figure: 5.Multigas analyzer [9]

\section{Results:}

After successful testing of the values of coconut fuel. The measured calorific values in bomb calorimeter are mentioned in the following table 2 . The total coconut has some considerable value but due to coir it having considerable ash content. Shell of the coconut having higher calorific value compare to all remaining components but in general we are using fuel it is combination [9] of all the parts of the tender coconut.

Table: 2 The CV and Ash content of coconut fuel.

Table: 2 The $\mathrm{CV}$ and Ash content of coconut fuel.
\begin{tabular}{|l|c|c|}
\hline Part name & Calorific value & Ash content \\
\hline Total coconut & $2750 \mathrm{Kcal} / \mathrm{kg}$ & $12 \%$ \\
\hline Shell & $3700 \mathrm{Kcal} / \mathrm{kg}$ & $9 \%$ \\
\hline coir & $1550 \mathrm{Kcal} / \mathrm{Kg}$ & $40 \%$ \\
\hline Coconut husk & $2600 \mathrm{Kcal} / \mathrm{Kg}$ & $11.5 \%$ \\
\hline Square type & $3500 \mathrm{Kcal} / \mathrm{Kg}$ & $10 \%$ \\
\hline
\end{tabular}

\section{Conclusion}

This is the best alternative to the peat coal. The calorific value is high in the case of square type pieces. The machining time and cost is little more comparing to other type. With the help of this fuel we can avoid peat coal which will directly reduce the emission from conventional furnace. The $\mathrm{CV}$ is more compare to peat so the cooking time reduced and net fuel consumption also very less. The tender coconut fuel releases less smoke which is having good smell which controls the mosquitoes. BY the help of this process the municipal wastage reduced and also which reduced harmful gases indirectly from dumping yard.

\section{Acknowledgements}

We are expressing our thanks to God for his grace.

We are highly thankful to Er.Basam.Koteswararao, Faculty, Maddawalabu University Bale Robe, Ethiopia -247 for his support throughout the work and his guide lines.

\section{References}

[1] B.Koteswararao, L.Ranganath, D.Ravi "Designing of a Coconut Chopping Machine and Making Fuel from Tender Coconut" Vol 9(34), September 2016.

[2] Rethinam, P. (2003). Prospects for the coconut industry. J. Planta. Crops. 31(1): 1-7.

[3] P.raman, N K Ram,ruche guptha , "To convert tender coconut husk into convenient form of fuel for clean combustion " Project Code 2010BE11,2011.

[4] K.Radha Krishna ,Fuel from Tender Coconut ,ISNCESR'16,17th \& 18th March 2016. 
[5] APCC. Coconut Food Process - Coconut Processing Technology. Information Document. Arancon, Jr, R.N.,ed. Asian and Pacific Coconut Community. Jakarta, Indonesia,1996.

[6] Brandis, C. and Glaser, F. (1973). Specification for separations of kernels from coconuts. Philippine patent No: 9865

[7] Rio Digital Bomb calorimeter, establishment 1973

[8] Pantron multi gas analyser model Mn 05

[9] K.siva kishore babu, Analysis Of Quality In Solid State Welding (Copper-Copper) By Using NDT And DT By Altering Physical Properties At Constant Time, Materials Today: Proceedings 4 (2017) 7351-7356

[10] B.Koteswararao et al 'Experimental Analysis of solar panel efficiency with different modes of cooling' International Journal of Engineering and Technology, Vol 8 No 3 Jun-Jul 2016.

[11] D.Ravi ' Investigation of Machining Parameter in EDM of High Carbon Steel Alloy (EN31)', Materials Today: Proceedings 4 (2017) 1375-1384 